\title{
Classroom Instruction Reinforcement Strategies and Factors that Influence their Implementation in Kenyan Primary Schools
}

\author{
Mary Wangari Kinyanjui \\ Kiambu Institute of Science \& Technology, Kenya \\ Dr Peter J.O. Aloka \\ Jaramogi Oginga Odinga University of Science and Technology, Kenya \\ Email:jairopeteraloka@yahoo.com \\ Dr Sr Sabina K. Mutisya \\ Catholic University of Eastern Africa, Kenya \\ Dr Sr Florentina Ndunge Ndeke \\ Catholic University of Eastern Africa, Kenya \\ Dr Naphtal Michira Nyang'ara
}

Laikipia University, Kenya

Doi:10.5901/jesr.2015.v5n3p267

\section{Abstract}

The study investigated classroom instruction reinforcement strategies and factors that influence implementation of the reinforcement strategies used by primary school teachers in the classroom in Kikuyu district of Kenya. The study was guided by the Operant Conditioning Theory. The study employed a Mixed Methods design in which both quantitative and qualitative data were collected. The target population teachers and pupils from public primary schools. Data was collected by using questionnaires and interview schedules. Quantitative data was analyzed using inferential statistics while Qualitative data was analyzed by using the thematic and content analysis. The study reported that social reinforcement in form of praise was the most popular reinforcement strategy used in classroom teaching followed by tangible items, activity and tokens in that order. The factors that affected implementation of reinforcement strategies by teachers during classroom instruction were class interest, social characteristics and delivery. Other factors were class size, gender, availability of reinforcers, class level and nature of content. The study recommends that teachers should carry out reinforcement assessment needed prior to using instructional reinforcement programs.

Keywords: Classroom, Instruction, Reinforcement, Strategies, Factors, Implementation, Public, Primary Schools

\section{Introduction}

Reinforcement is any consequence that strengthens behavior. Slavin (2009) stipulates that a reinforcer is defined as any consequence that strengthens behaviour. On the other hand Winkielman (2005) defines reinforcement as a stimuli, settings and antecedent that strengthen behaviour and increase the frequency of its expression. Moreover, reinforcement is a term in operant conditioning theory guide and behaviour analysis for process of increasing the rate or probability of behaviour, in the form of response delivered shortly after performing the behaviour. Reinforcement theory is based on behavioristic approach which affirms that behaviour is a function of its consequences (Winkielman, 2005). Classic learning theorists Watson and Skinner; Thordike, all regarded reinforcement as an essential component of successful learning. Watson investigated the effects of reinforcement on changing behavior and attitude towards learning. Skinner (1969) and Thordike $(1968,1970)$ first experimented on the effectiveness of various reinforcers on animals and subsequently transferred their interests and research activities to human beings (Slavin, 2009). In addition, Skinner 
conducted exhaustive studies of learning responses to several schedules of reinforcement. Fredrick Skinner later designed contingencies of reinforcement for an ideal learning culture. Hull and Thordike (1946) suggested that a reinforcer is sort of catalyst that strengthens behaviour. Skinner, (1969) experimented on the effectiveness of various reinforcers on animals and subsequently transferred their interest and research to activities to human beings (Slavin, 2009).

In the teaching profession, it is common for teachers to reach a point where they feel that their students could need a little extra push to keep them on track. This occurs when productivity is lagging in the classroom and students are less engaged than they were at the beginning of a school calendar year. Teaching success occurs when desired behavior has been adequately reinforced (Cotton, 2008). Apparently, teachers can control learning by providing instructional reinforcement when the student makes a move to the desired direction. It is important to note that the effectiveness of the reinforcement must be demonstrated. We cannot assume that a particular consequence is a reinforcer until we have evidence that it strengthens behavior for a particular individual. Sweets for instance can be considered reinforcers for young children. However, after they have had a big meal, children might not find sweets pleasurable and some children may not like sweets at all (Slavin, 2009). Slavin, (2009) gives one general guiding principle of classroom reinforcement, that, it is best to use the least elaborate or tangible reinforcement that will work. In other words, if praise works don't use grades or certificates. If grades work don't use toys and if toys work don't use food. Teachers should not hesitate to use whatever practical reinforcement necessary to motivate the learner's to carry out important learning tasks. If possible, teachers should try positive reinforcement strategies before even thinking of punishment. Garber (2006) adds that reinforcement strategies in classroom instruction can promote academic achievement and builds students' character. According to Carol, millions of children go to school everyday. Their parents and caretakers hope that their young children are treated with core values, care, and inspiration and will be educated in schools. The students themselves have expectations too. They hope that they will get along with their teachers, peers, have their worlds measured up and enjoy the process of learning. These hopes largely depend on proactive teachers who will provide them with positive instructional reinforcement in the classrooms. Reinforcement strategies in classroom teaching are important factors that influence school learning (Marzano, \& Pickering, 2007). Instructional reinforcement strategies are significant to a successful teacher's delivery of instruction. In particular, if teachers have high expectations of all their students, then positive reinforcement, encouragement, feedback and praise will come naturally and students will have an appreciation for learning and will be motivated to do well (Herrell, 2007).

In Kenya, the failing standard of education in public schools is supposedly due to lack of reinforcement and motivation (Cherop, 2010). Statistics add that students in public schools need ample time, opportunity to learn and encouragement. Furthermore, reinforcement approaches if well applied, would stir up interest in the students to learn and engage them fully in academic activities (MOE, 2013). Apparently for most part of the calendar year, the learner is with the teacher (MOE, 2013). Sivi (2007) decries the poor academic performance in public primary schools compared to private schools as shown by the following table. According to Sivi (2007), from the year (2005) to date, there has been poor academic performance in public primary schools in Kikuyu District. In the year 2005 for instance, schools in the division were ranked $5^{\text {th }}$ in a list of 100 schools from last in Central Province (MOE, 2005). Kikuyu constituency has a high concentration of private schools with an enrollment of $50 \%$ of the total number of students in primary schools (MOE, 2013). Poor performance is caused by peer influence where learners influence one another in misbehavior. Moja (2010) stipulates that poor motivation of teachers and learners has an effect on academic performance.

\section{Theoretical Framework and Literature Review}

\subsection{Operant Conditioning theory}

The study was guided by the reinforcement theory propounded by B.F. Skinner. The theory is known as behaviorism or operant conditioning which is still commonly taught in psychology today. The theory states that an individual's behavior is a function of its consequences (Winkielman, 2005). For example if an individual's behaviour is immediately followed by pleasurable consequences, the individual will engage in that behaviour more often which is referred to as operant conditioning. In the classroom setting in public primary schools during instruction, learning behaviour could be strengthened by consequences or rewards and in turn make progress in their academic work (Alberto \&Troutman, 2006). The operant conditioning theory informs the present study in that as the proponent, Fredrick Skinner explains that some human behaviour is clearly prompted by specific stimuli. This is quite relevant in the classroom setting where learners under instruction require prompting by their teachers. Skinner's work proposed a class of behaviour which he labeled 
operant because they operate on the environment in the apparent absence of any unconditional stimuli. Skinner's work is focused on the relations between behaviour and its consequences. For example if an individual's behavior is immediately followed by pleasurable consequences, the individual will engage in that behavior more often which is referred to as operant conditioning. In the classroom setting in public primary schools during instruction, learning behaviour could be strengthened by consequences or rewards and in turn make progress in their academic work (Alberto \&Troutman, 2006). Furthermore, principles of behavioural learning include the role of consequences, reinforcers, immediacy of consequences and schedules of reinforcement (Biggie \& Shermis, 2005).

\subsection{Literature review}

Previous studies have been carried out on the classroom instructional reinforcement strategies. For example, Burnet, (2006) investigated the students' perceptions of the frequency of teacher feedback and praise as reinforcement strategies in New South Wales and found that, effort feedback impacted directly on students' relationships with their teachers. The age analysis of the teacher feedback as a reinforcement strategy indicated that ten year old students reported to have valued praise more frequently than the younger students and the older student. Seda, (2008)'s study on classroom management approaches of primary school teachers in Turkey, reported that, students should be encouraged to propose and negotiate for some reinforcement strategies they value, group work is necessary for students' social and cognitive development, teachers should function like learners' companions in the classroom and if the classroom strategies do not work, they should be replaced with new ones. Although the study in turkey surveyed effective reinforcement strategies in the classroom teaching, Seda, (2008) did not explore the schedules of reinforcement employed. Another study by Maori, (2008) investigated the classroom management strategies among 50 selected teachers in a New York school. The findings revealed that most teachers reported to using social reinforcement such as verbal praise, positive feedback, use of tokens, use of privileges such as extra computer time, positive touching and positive note home to parents.

Another research was conducted by Maini, (2011), in Ontario Canada on the pro-active approach to behavior in class with students as respondents. Findings indicated that after teachers used reinforcement in the form of rewards and antecedent strategies, the majority of students benefited in academic achievement. Wafula, Malimbe and Kafu, (2011) in their study, presupposed that reinforcement in the secondary school classroom in Kenya aims at encouraging student's positive academic achievement, teacher efficacy and in a nutshell effective teaching and learning. The findings revealed that positive reinforcement was more elaborate and often used by the teachers in the classroom management. The findings were that forms of incentives are good in themselves but those that tend to be material in nature, should not be frequently used. This is because students might perform the task for the sake of the reward. The study concluded that positive reinforcements are essential techniques in classroom learning behaviour management. Another study by Dillion \& Wanjiru, (2013) investigated the reinforcement strategies for teachers and learners of English in an urban primary school in Kenya. The findings indicated that positive reinforcement was more impactful and elaborate often used by the teachers in the classroom management. Moreover, the findings revealed that forms of rewards and appraisal are good in themselves in reinforcing learners.

Studies have also been carried out on the factors influencing instructional reinforcement strategies in classroom teaching. For example, Apiola (2013) studied the contextual factors that influence motivation in student learning in Finland Research design used was survey with qualitative and quantitative paradigms. The study sample comprised 144 students of middle level grades. Findings indicated that contextual factors such as the learning environment affect students' motivation in learning. Ali (2010) investigated factors that affect implementation of instructional reinforcement in Saudi Arabia. Ali sampled 231 participants out of which 150 were males and 81 were females of college level and used the Survey design. Findings indicated that factors that facilitate reinforcement include relevance of reinforcers to students during instruction, setting clear objectives, relevance of content and encouragement by lecturers in teaching. Factors that hinder implementation of reinforcement include unscheduled activities given to learners and lack of guidance in learning tasks. Photini (2010) studied motivation hinges on students' learning in Spain. Questionnaires were used to interview 70 students of middle level grades and the findings indicated that some of the hindrances to students' motivation in learning were: students' poor perception of their abilities to succeed, lack of teachers' knowledge of the students interests, lack of stimulation of students' imagination and lack of gender sensitivity on the part of the teacher. While the reviewed study used one type of instrument for data collection, the present study used a variety of instruments to triangulise data collection. In another study, Hang (2011) investigated factors affecting motivation of students learning English as a second language in Vietnam. Qualitative data analysis identified three processes identified three main factors influencing 
students' motivation to learn English language. The factor included: biased students perceived values of English knowledge, educational environment and family social works. Other factors involved inter-cultural contact with the target language and Vietnamese cultural practices.

In addition, it appears that there is very scanty literature done on classroom reinforcement in Kenya. Further, the results of the study would be significant to the teacher educators and trainers since they could borrow a leaf on how to design, select or use practical reinforcement strategies while training student teachers in educational institutions.

The study was guided by the following research questions:

- What types of reinforcement strategies are used by teachers in the classroom during instruction in Kikuyu District, Kenya?

- What are the factors that influence the implementation of reinforcement strategies in Kikuyu District, Kenya?

\section{Research Methodology}

\subsection{Research design}

The study employed qualitative and quantitative research paradigms. From the quantitative paradigm, the descriptive survey design was used. The descriptive survey design was used since it is designed to collect information that describes, explores and help the researcher to investigate population based on sampling (Kothari, 2010).For the qualitative paradigm, the interviews were used. Interview guides were used in the study since it is a purposeful undertaking by the researcher who interrogated subjects on a given situation to collect needed information.

\subsection{Study participants}

The target population for this study consisted of teachers in 30 public primary schools in Kikuyu District ( $\mathrm{N}=30$ ), Kenya. The study targets 100 teachers and 250 students from all the 30 public primary schools in Kikuyu District, Kiambu County of Kenya. The sample frame was (30) public primary schools, 200 pupils who will be drawn from standards four to seven and 100 teachers.

\subsection{Research instruments}

Questionnaires give a relatively objective data. The questionnaire for pupils and teachers were structured based on the main research questions namely; classroom reinforcement strategies, schedules of reinforcement and effective reinforcement strategies, except for the section (I) which covered demographic characteristics of the respondents. For pupils, this section included gender, age group, and class, while for teachers the section included age, gender and qualifications. The researcher also used semi-structured interviews which involved structured questions and use of open forms to probe more deeply in order to obtain additional information. Interview guides were administered to teachers randomly and purposely sampled. The research instruments were reviewed for validity by various groups of people who included the researcher's peers and supervisors at the Catholic University of Eastern Africa, Nairobi Kenya. Split half measures how the instrument measures the construct of interest and assumes that if all the items are drawn from the same domain, the two halves should highly correlate as computed by person product moment coefficient. Credibility of data was enhanced by designing the research procedure, combining research designs hence qualitatively and quantitatively rather than using one design in other words, triangulation in research. Further, competence interviewer debriefer was ascertained by participants reading a summary of final results for comments. To ensure transferability of data, a file with a complete set of data analysis is available upon request so that other researchers can transfer the conclusions of the study to other cases or to repeat the procedure.

\subsection{Data collection procedures}

Permission to carry out the study was first obtained from The Catholic University of Eastern Africa, Nairobi Kenya and then two approved copies of research proposal were forwarded to the Ministry of Education Kenya for issuance of research permit. As per the requirements, the researcher then reported and gave copies of the permit to the relevant authorities of the area of the study for clearance. The researcher then visited the selected schools to personally administer the questionnaires to teachers and pupils. The interview schedule was be planned and organized by the 
researcher and the head teachers as agreed. After distributing the questionnaire to the teachers, the researcher also clarified some issues concerning responses to the questionnaire. The researcher also administered interviews with selected participants and each interview lasted about thirty minutes. The interviews were tape recorded.

\subsection{Data analysis}

Data analysis is the process of bringing order and meaning to raw data Kothari, (2011). The collected data was analyzed using both quantitative and qualitative data techniques. Descriptive analysis such as frequencies and percentages were used to present quantitative data collected from teachers and pupils using questionnaires. Qualitative data from the interview guides were analyzed using thematic framework. Information divided into themes, coded thematically then analyzed systematically. Quantitative data was analyzed using SPSS version 21. The inferential statistics such as Chisquare and factor analysis were used. The quantitative and qualitative results obtained were both integrated.

\section{Findings and Discussion}

\subsection{Findings on Reinforcement Strategies as used by Teachers in the Classroom during Instruction}

The study sought to find out the types of reinforcement strategies used by teachers in classroom during instruction. Therefore, various related items were constructed in the pupils and teachers questionnaires respectively. The findings from teachers' responses are presented in Table 1.

Table 1: Teachers responses on Reinforcement Strategies

\begin{tabular}{lcc}
\hline Strategy & Frequency & Percent \\
\hline praise & 81 & $83 \%$ \\
Tangible items & 64 & $65 \%$ \\
Games and playtime & 49 & $50 \%$ \\
Money, points & 21 & $21 \%$ \\
\hline
\end{tabular}

The findings in Table 1 indicate that $83 \%$ of the teachers used "praise" as a reinforcement strategy duding their instruction. There were $65 \%, 50 \%$ and $21 \%$ of the teachers who indicated that they used "tangible items", "games" and "playtime" and "money" or "points" for reinforcement respectively. The findings showed that, praise was the most popular reinforcement strategy. These findings agree with Maori (2008) who found out that most teachers reported to using social reinforcement such as verbal praise. This could be due to the operant conditioning theory guide and behaviour analysis for process of increasing the rate or probability of behaviour, in the form of response delivered shortly after performing the behaviour. Therefore, most teachers are likely to embrace praise as a reinforcement strategy that is readily available at the time of the desired behaviour occurrence.

According to the findings in Table 1, tangible items were the second most popular strategy of reinforcement as indicated by the teachers in this study. The findings also show that, $65 \%$ of the teachers who participated in this study used tangible items as reinforcement. The findings contradict with Wafula, Malimbe and Kafu, (2011) who established that that forms of incentives are good in themselves but those that tend to be material in nature should not be frequently used. As shown by the findings, teachers prefer material items as effective strategy in reinforcing instruction. Another reinforcement strategy presented in table 1 is games and play time. There were $50 \%$ of the sampled teachers who indicated that they gave learners games and play time as reinforcement. This could be in line with the adage that too much work without play makes Jack a dull boy. Considering that all the pupils who participated in this study were in primary school, then games and play time can be a very significant element of their life as they are still growing up. The findings agree with Maini (2011) who indicated that after teachers used reinforcement in the form of rewards and antecedent strategies. The implication of the findings is that, play time and games could be some of the antecedent strategies that the teachers can use in order to ensure high academic achievement.

\subsubsection{Findings on Reinforcement Strategies}

The researcher also sought from the pupils' information on reinforcement strategies used by their teachers during instruction. Their responses were as shown in Table 2. 
Table 2: Pupils responses on Reinforcement Strategies

\begin{tabular}{lcc}
\hline & Frequency & Percent \\
\hline Do your teachers praise you when you do well on class? & & \\
Yes & 183 & 91 \\
No & 19 & 9 \\
Total & 202 & 100 \\
Strategy used by teachers & & \\
Applauding & 50 & 30 \\
Through gifting & 98 & 58 \\
Encouraging me to work harder & 21 & 12 \\
\hline
\end{tabular}

The researcher sought to know from pupils whether their teachers praised them when they did well in class or not. From findings in Table 2, $91 \%$ of the pupils admitted that their teachers praised them while only $9 \%$ of them stated otherwise. These findings confirm those from the teachers which reported that, praise was the most popular among all the reinforcement strategies employed by teachers in classroom instruction. It is evident from Table 2 that gifting was the most popular strategy among the pupils who participated in this study. There were $58 \%$ of the pupils who received gifts from their teachers as reinforcement. The findings from learner participants differ from those of the teachers which showed that praise was the most popular among all the reinforcement strategies employed by teachers in classroom instruction. Applauding and encouragement to work harder had 30\% and 12\% respectively. The students' responses regarding contradict those raised from the teachers which indicated that praise is the most favourite strategy among the teachers.

Interviews were also carried out from teachers respondents on types of reinforcement strategies used in classroom instruction. The participants affirmed that, they used reinforcement strategies during instruction. The themes reported revolved on aspects such as social reinforcement, tangible reinforcers, activity reinforcers and group reinforcers. The participants reported having adopted social reinforcement. All the teachers interviewed agreed that social reinforcement was the most commonly used reinforcement strategy in classroom teaching. Ten out of the twenty teachers interviewed reported that they supplement verbal praise with written positive remarks in the pupil's written work, good grades attention and recognition for exemplary work among others which the pupils value. These findings concur with the study by Burnet (2006) whose study found out that when teachers use such strategies like praise, the younger children aged ten value the reinforcement more than the older ones. This implies that the younger learners value social reinforcement more than the older learners. Some participants also reported on the use of tangible reinforcers. For example, five agreed that they occasionally use simple items such as pencils, rubbers and exercise books when affordable, appropriate and available. One young female teacher complained in the excerpt:

"I always wish I had several tangible items no matter how simple, so that I could use them as rewards when learners perform well in class."

This excerpt means that teachers desire to use tangible reinforcers in classroom instruction but are frustrated by their unavailability. The implication here is that such simple items are practical reinforcers and every effort should be made to avail them so that teachers could use them as reinforcers when teaching in the classroom.

The findings also indicated that some teachers used activity reinforcers. For example, some teacher respondents explained that that they used activity reinforcements like time to play outside the classroom as a reinforcement strategy. This is in line with Wafula et al (2011) concept that incentives that tend to be material in nature should not be overused but instead, they should be alternated with other types of reinforcers like games and activities or computer time. This is because learners may perform tasks for the sake of material rewards. A majority of the respondents expressed that reinforcement strategies no matter the type encouraged learners to perform well academically. Moreover, Wafula et al (2011) proposed that positive reinforcement techniques are essential in managing classroom learning process and have a role in learner's academic achievement. The findings of the study also contrast Maori's (2008) research findings that recently trained teachers used a variety of classroom reinforcement strategies. According to the current study findings, the older the teachers are in terms of teaching experience, the more creative they are in alternating reinforcement strategies in classroom teachings. Some of them improvise tangible items to reinforce learners and others use strategies such as displaying exemplary work for others to see as reinforcers.

Finally, the participants also reported to have used group reinforcers in classroom. However, another group of the 
more experienced teachers indicted that they used group and whole class reinforcement strategies. In addition, they also explain to the learners that they should earn their own reinforcers with effort. This concurs with Wong and Wong (2009) who suggested that whole class reinforcers are very effective in strengthening learning behaviour. This implies that learners should not merely receive reinforcers; instead, they should learn to earn them. A few teacher respondents revealed that they used information feedback as a reinforcement strategy. This is in line with Hardin (2012) whose findings indicate that feedback allows learners to receive satisfaction for any learning progress they make. This implies that getting satisfaction from progress made in academics is a much better way of reinforcement as compared to close monitoring. The implication of this study is that depending on the circumstances, either continuous or partial reinforcement schedules may be effective.

\subsection{Findings on Factors that influence the implementation of reinforcement strategies}

The study sought also to find out some of the factors that influence the implementation of reinforcement strategies in the classroom. The results are presented in Table 3

Table 3: Quantitative results on factors that influence implementation of reinforcement strategies

\begin{tabular}{lccccc}
\hline Factors & Strongly Agree & Agree & Undecided & Disagree & Strongly Disagree \\
\hline Gender & $26(26.5)$ & $29(29.6)$ & $14(14.3)$ & $17(17.3)$ & $12(12.2)$ \\
Age & $40(40.8)$ & $39(39.8)$ & $5(5.1)$ & $12(12.2)$ & $2(2.0)$ \\
Level & $40(40.8)$ & $37(37.8)$ & $19(19.4)$ & $2(2.0)$ & $0(0)$ \\
Interests & $34(34.7)$ & $39(39.8)$ & $13(13.3)$ & $11(11.2)$ & $1(1.0)$ \\
Availability & $33(33.7)$ & $40(40.8)$ & $17(17.3)$ & $6(6.1)$ & $2(2.0)$ \\
Effectiveness & $54(55.1)$ & $25(25.5)$ & $15(15.3)$ & $3(3.1)$ & $1(1.0)$ \\
Class size & $41(41.8)$ & $33(33.7)$ & $11(11.2)$ & $11(11.2)$ & $2(2.0)$ \\
Nature of content & $45(45.9)$ & $35(35.7)$ & $16(16.3)$ & $1(1.0)$ & $1(1.0)$ \\
\hline
\end{tabular}

The results in Table 3 indicate that some of the factors that affect reinforcement strategies used by teachers in classroom teaching include; gender, age, level, interests, availability, effectiveness, class size and nature of content. These findings agree with Maini (2011) who found out that, that reinforcement strategies can be incorporated by the teachers into their daily repertoire of classroom behavior management skills. Therefore, these findings are pointing out that there are several factors that affect reinforcement strategies used by teachers. Due to this, it is expected that every teacher gets the necessary education and get equipped with the relevant skills for the reinforcement. The results in Table 3 also shows that, $73 \%$ of the teachers who participated in this study agreed that "interest" influences the reinforcement strategies used in classroom by the teachers. This is an indicator that intrinsic motivation plays a key role in influencing which strategy a teacher uses. Other results show that, availability of the reinforcement is a factor to consider in reinforcement. This is in confirmation of the earlier findings which showed that incentives such as money and tokens are rarely used by the teachers. This could be due to the fact that the teachers may find it a big challenge to spend money as reinforcement each time they go to class. Therefore, this confirms why most teachers who participated in this study felt that they rarely gave money as reinforcement in classroom instruction.

To ascertain the factors that significantly influence reinforcement strategies in teaching, a factorial analysis was carried out.

\subsubsection{Factor Analysis results of Factors Influencing Reinforcement Strategies}

The study found out the main factors that influenced the selection and implementation of classroom reinforcement strategies by teachers. The results in Table 4 were generated from the factor analysis. 
Table 4: Total Variance Explained

\begin{tabular}{|c|c|c|c|c|c|c|c|c|c|}
\hline \multirow[t]{2}{*}{ Component } & \multicolumn{3}{|c|}{ Initial Eigenvalues } & \multicolumn{3}{|c|}{ Extraction Sums of Squared Loadings } & \multicolumn{3}{|c|}{ Rotation Sums of Squared Loadings } \\
\hline & Total & $\%$ of Variance & Cumulative \% & Total & $\%$ of Variance & Cumulative \% & Total & $\%$ of Variance & Cumulative \% \\
\hline 1 & 2.277 & 28.457 & 28.457 & 2.277 & 28.457 & 28.457 & 1.848 & 23.100 & 23.100 \\
\hline 2 & 1.312 & 16.397 & 44.855 & 1.312 & 16.397 & 44.855 & 1.486 & 18.575 & 41.675 \\
\hline 3 & 1.159 & 14.493 & 59.348 & 1.159 & 14.493 & 59.348 & 1.414 & 17.672 & 59.348 \\
\hline 4 & .908 & 11.346 & 70.693 & & & & & & \\
\hline 5 & .750 & 9.371 & 80.065 & & & & & & \\
\hline 6 & .596 & 7.455 & 87.520 & & & & & & \\
\hline 7 & .541 & 6.767 & 94.287 & & & & & & \\
\hline 8 & .457 & 5.713 & 100.000 & & & & & & \\
\hline
\end{tabular}

Extraction Method: Principal Component Analysis

According to the results in Table 4, there were eight factors in this study. However, only three components were above 1.0 as shown in the Table 4. The analysis results show that three components were selected in this study. These components are as illustrated in Table 5.

Table 5: Rotated Component Matrix (a) on factors influencing instructional reinforcement such as class size, availability, gender etc.

\begin{tabular}{|c|c|c|c|}
\hline & & mpon & \\
\hline & 1 & 2 & 3 \\
\hline Reinforcement Strategy used in teaching (Class Size) & .820 & & \\
\hline Reinforcement Strategy used in teaching (Interests) & .754 & & \\
\hline Reinforcement Strategy used in teaching (Availability) & .694 & & \\
\hline Reinforcement Strategy used in teaching (Age) & & .772 & \\
\hline Reinforcement Strategy used in teaching (Gender) & & .703 & \\
\hline Reinforcement Strategy used in teaching (Level) & & .586 & 414 \\
\hline Reinforcement Strategy used in teaching (Nature of Content) & & & .753 \\
\hline Reinforcement Strategy used in teaching (Effectiveness) & & & .743 \\
\hline
\end{tabular}

Extraction Method: Principal Component Analysis. Rotation Method: Varimax with Kaiser Normalization. A Rotation converged in 5 iterations.

The results in Table 5 show the components that were extracted from the factor analysis. According to the results, three components were extracted from this factor analysis. The first component comprises of class size, interest, and availability. These three generate a theme of "class interest" as a major factor that influences the reinforcement strategy used by a teacher during classroom instruction. The second component, "social characteristics" is emerging from age, level and gender while the third component, "delivery", has been generated by nature of content and effectiveness. Therefore, these results show that "class interest", "social characteristics" and "delivery" of content were strong factors that affected the reinforcement strategies implemented by teachers during classroom instruction. The implication of these results is that teachers should study the interest of their students before selecting reinforcers.

Interviews were also carried on factors that influence implementation reinforced in the classroom learning. Qualitative data was obtained on factors that influence implementation of reinforcement strategies in classroom instruction such as class size, interests of the learners, gender, availability of reinforcers, class level and nature of content. The participants reported that Students' perception influenced implementation of strategies. Half of the participants interviewed cited that themes such as the attitude of the learners towards the reinforcement provided is a factor that affects implementation of reinforcement in the classroom. The themes revolved around the attitude of the learner towards classroom instruction. This is similar to Photini (2010) whose findings indicated that students' poor perception of their ability to succeed is a major hindrance to learners' motivation. In addition, Hang (2011) in his study reported that, students' biased perceived value of reinforcement affects the performance and implementation of the instructional reinforcement in the classroom.

Secondly, Interest of learners also featured in the interview as some participants cited that it was difficult to 
understand some of the learners' interest in some settings. Another factor cited by participants that affects the implementation of classroom reinforcement was transition of learners' from one class to another as one female teacher reported the excerpt:

"In my opinion, what really affects instructional reinforcement is the fact that once you have understood the learners well enough to reinforce them effectively, they are handed over to another teacher in the next class level. The new teacher and I have to start all over again with new learners which are rather disappointing."

This transcript means that when the learners are through with one level they are handed over to another teacher regardless of the fact that the previous teacher understood what reinforcers worked with those particular learners. The implication here is that before the teacher learns what reinforcers are suitable for the new lot, they will experiment with any type of reinfocers as a matter of chance which causes inconsistence in stimulus application. In contrast to Hang (2011) findings that that lack of teachers' knowledge of the students' interest is a hindrance to reinforcement implementation, the researcher found that teachers have sufficient knowledge of their students' interests and level of understanding.

A majority of the teachers' respondents reported that the class size or population of learners in a particular class level affects the implementation of reinforcement in classroom teaching. Most of them handle classes of over forty learners and they find it difficult to reinforce individual learners effectively. Consequently, most of them result to the whole group or whole class reinforcement. Another finding was that Teachers' Preference influenced the reinforcement strategies. This may greatly affect the performance in contrast with Seda (2008), who recommended that students should be encouraged to propose and negotiate for some reinforcement strategies they value. "Availability of reinforcers" featured as one of the strategies. Almost all respondents interviewed remarked that they do not have tangible items or tokens at their disposal to use as reinforcers. This is due to financial constraint or lack of administrator's involvement in allocating budget to reinforcement program. As a result, there is over reliance on social reinforcers that include praise, attention and warmth, feedback, followed by approval, showing concern, recognition and empathy. Slavin (2009) gives a general guiding principle of classroom reinforcement which aids teachers to avoid overreliance on certain types of reinforcers. He recommends that it is best to use the least elaborate social or tangible reinforcement that will work. In addition, teachers should not hesitate to use whatever practical reinforcement necessary in order to motivate learners and encourage them to carry out learning tasks. Wafula, et al, (2011) advice teachers to try positive reinforcement strategies before thinking of any negative reinforcement strategies, since they are essential techniques in managing learning behaviour.

The study also found out that gender did not feature a lot among factors that affect implementation of reinforcement. Most teachers interviewed reported that they reinforced learners the same way regardless of gender. The implication of the finding is that teachers ignored the fact that gender may guide them to establish the interest of the learners. This in turn may affect a factor necessary in the selection of the reinforced strategy to be used in reinforcing the learning process of individual pupils. However, they do not concentrate too much on gender sensitivity in their choice and implementation of reinforcement strategies since they don't think it is important. One female teacher reported the following in her excerpt:

"I don't think it is right to discriminate the learner based on gender when reinforcing the learning process. I reinforce pupils the same way."

The implication here is that gender does not affect the selection and implementation of reinforcement strategies. Generally, all participants interviewed cited that factors which affect performance of reinforcers are: qualities of reinforcers, rate and delay of reinforcement. .This means that the immediacy of reinforcement is important in teaching and learning. Teachers should not withhold reinforcement until so much later. Another small group of participants reported that the classroom environment supports and complements the reinforcement in use. This is similar to Apiola (2013) whose findings indicated that contextual factors such as the learning environment affect student's motivation in the learning process. According to Apiola, if the environment does not offer sufficient support for requisite learning development, then the learners are discouraged from engaging in higher learning tasks. Sufficient guidance by the teacher is another factor that affects motivation of learners in their learning process. Once the teacher is warm, the learners feel reinforced and encouraged. This implies that the teachers' warmth towards learners is reinforcing in itself. 


\section{Concluding Remarks}

The study investigated classroom instruction reinforcement strategies and factors that influence implementation of the reinforcement strategies used by primary school teachers in the classroom in Kikuyu district of Kenya. The study reported that social reinforcement in form of praise was the most popular reinforcement strategy used in classroom teaching followed by tangible items, activity and tokens in that order. The factors that affected implementation of reinforcement strategies by teachers during classroom instruction were class interest, social characteristics and delivery. Other factors were class size, gender, availability of reinforcers, class level and nature of content. According to the findings of this study, most teachers faced serious challenges in implementing classroom reinforcement strategies due to class size, nature of content, interest availability of reinforcers among others. Teachers implement classroom reinforcement strategies quite often in their day to day teaching. However, this does not omit a few of these teachers who did never bother to reinforce their learners. Although most teachers shunned away from giving money and other tangible items, these were the learners' favourites. This study concludes that classroom reinforcement strategies vary in effectiveness and should therefore be carefully selected. Owing to this, a teacher is likely to embrace any of the reinforcement strategies at his disposal. However, caution must be taken to avoid strategies that may be way beyond the teacher's means. The teacher should be keen to pay close attention to factors such as class size and the nature of content to be delivered among others before settling down on any given strategy. Perhaps the most important factor to bear in mind is that reinforcement strategies and their effectiveness in implementation are not independent of each other. There is a relationship between the classroom reinforcement strategies used and their effectiveness.

Based on the findings of the study, several recommendations were made to teachers, school administrators, Ministry of Education, learners, parents and teacher educators. Administrators should plan for budgetary allocations in order to purchase reinforcers in terms of tangible items and tokens. Further school administration should start involving parents in reinforcement programs. In other words, parents could partner up with teachers in reinforcement programs for academic success and achievement. This means that learners could be reinforced at home for desirable purposes and other times in school. This will go a long way in varying reinforcement instead of the present scenario where teachers over rely on social reinforcement due to unavailability of other reinforcers. Teachers should lobby with administrators and parents for token economy programs which have long term effect on as compared to social reinforcers. Similarly, it is also equally important for teacher trainers or educators to deepen the teacher trainees' knowledge on token economy programs and not merely babbling through their syllabuses. If teachers are well informed in ideals involving reinforcement strategies, they will handle reinforcement programs competently for academic success. It is the responsibility of the teacher to carry out reinforcement assessment needed prior to using instructional reinforcement programs in order to ensure their success. The assessment will assist the teacher to heed to all learner's individual needs and interests. Nevertheless, learners should be allowed to suggest types of reinforcement strategies which they value. The type of rewards should depend on learners' demonstration of appropriate behaviour. Improvement too should be reinforced and teachers should wait until learning processes are perfect to deliver reinforcement. Teachers or parents should match the rewards with learning behaviour being demonstrated. Further, it should be made clear to the learners what reinforcement is purposed to do. The reinforcer should be available promptly and must be delivered consistently according to a planned schedule. Emphasis should be laid on the use of reinforcement strategies that are likely to bring about intrinsic motivation to learners. In other words, extrinsic reinforcement should eventually graduate to intrinsic reinforcement. In addition, individual attention should be emphasized on in an attempt to cater for the needs and interests of the learners. This can only be achieved if the teacher-pupil ratio is improved by reducing the population in the present classroom in public primary schools.

From the findings of the study, there are suggestions for further research. For example, a similar study should be carried out in other counties especially in an urban set up and in private primary schools. The results would be used to establish the classroom reinforcement strategies used in the urban set up and in private schools for comparison with their counterparts in rural areas or in private schools. Further research study needs to be undertaken to include other classroom instruction tasks that have not been included in this study.

\section{References}

Alberto, P. \& Troutman A., (2006). Applied Behaviour Analysis for Teachers. $7^{\text {th }}$ Edition Upper Saddle River, Prentice Hall Merriel. Ali, A., (2005). Requirements and Benefits of Effective Instruction. Unpublished thesis, University of Riyadh, Riyadh, Saudi Arabia. Apiola, M., (2013). Creative-Supporting Learning Environments. Unpublished thesis, University of Helsinki, Finland. Biggie, M. L. \&Shermis, S. S. (2005). Learning Theories for Teachers, $6^{\text {th }}$ Edition. Pearson, Boston. 
Burnet, W. (2006).Relationship Between Student's Perception of The Frequency of Teacher's Feedback and Praise. University of New Wales Australia.

Cherop, J. (2010). Motivating Students in the Classroom. Unpublished Masters Thesis, Catholic University of Eastern Africa, Nairobi Kenya.

Cotton, C. (2008). Classroom Reinforcement. Herbert Welberg, University of Illinois, Chicago, USA.

Dhillion, J. \& Wanjiru, J (2013). Challenges and Strategies for Teachers and Learners of English as a Second Language: The Case of an Urban Primary School in Kenya. Journal of English Linguistics, Volume 3, No. 2, 14-24.

Garber, C. (2006). The Positive Classroom, Volume 66. American Association of Curriculum Developer.

Hang, P. (2011). Factors affecting motivation of students learning English as a second language. Unpublished thesis, University of Otago, New Zealand.

Hardin, C. J. (2007). Effective Classroom Management, Models and Strategies for today's Classroom. $3^{\text {rd }}$ Edition Pearson Publishers, Boston U.S.A.

Herell, F. (2007). Constructivist Teaching Strategies for Diverse Middle Level classrooms, Pearson Publisher., Boston U.S.A.

Kothari, C.R, (2011). Research Methodology. New Age International (P) Limited, New Delhi.

Maini, R. (2011). Teacher Training in a Proactive Approach to Classroom Behaviour Management. Unpublished PhD Thesis, University of Toronto, Canada.

Maori, T. (2008). Classroom Management Strategies. Unpublished Masters Thesis. University of Christ Church, New Zealand.

Marzano, R., and Pickering, D. (2007). The Case for and Against Homework. Educational Leadership. Alexandria, V. A.

Ministry of Education, (2013). Quality Education For Sustainable Development. Ministry of Education, Nairobi.

Moja T (2010). An analytical synthesis of school performance.World Bank Document. Retrieved on $2^{\text {nd }}$ August 2014 from http//wiki,answers. com/Q.

Photini, J., (2006). Teaching Methods In The 21st Century, Pearson Publishers, Spain.

Sivi, K. (2009). Social Issues Affecting Education. Kikuyu Strategic Plan website. Government Press, Nairobi.

Slavin, R. (2009). Educational Psychology: Theory and Practice (9th edition). Pearson International. Columbus, Ohio.

Wafula, A., Wakhungu G., and Kafu P. (2011). The State of Positive Reinforcement in Public Secondary Schools in Eldoret Municipality. International Journal of Current Research, Volume 3, Issue 11, 38-70.

Winkielman, P. (2005). Cognitive Psychology. Guilford: New York, USA.

Wong, H. and Wong, W. (2009). The First Days of School and How To Be an Effective Teacher. Harry K. Wong Publishers Inc. New Jersey. 
